\title{
Diminishing covariation bias in women with a negative body evaluation and the potential roles of outcome aversiveness and interpretation of social feedback
}

Citation for published version (APA):

Alleva, J. M., Stuijfzand, B. G., \& Martijn, C. (2018). Diminishing covariation bias in women with a negative body evaluation and the potential roles of outcome aversiveness and interpretation of social feedback. Body Image, 24, 62-68. https://doi.org/10.1016/j.bodyim.2017.12.002

Document status and date:

Published: 01/03/2018

DOI:

10.1016/j.bodyim.2017.12.002

Document Version:

Publisher's PDF, also known as Version of record

Document license:

Taverne

Please check the document version of this publication:

- A submitted manuscript is the version of the article upon submission and before peer-review. There can be important differences between the submitted version and the official published version of record.

People interested in the research are advised to contact the author for the final version of the publication, or visit the DOI to the publisher's website.

- The final author version and the galley proof are versions of the publication after peer review.

- The final published version features the final layout of the paper including the volume, issue and page numbers.

Link to publication

\footnotetext{
General rights rights.

- You may freely distribute the URL identifying the publication in the public portal. please follow below link for the End User Agreement:

www.umlib.nl/taverne-license

Take down policy

If you believe that this document breaches copyright please contact us at:

repository@maastrichtuniversity.nl

providing details and we will investigate your claim.
}

Copyright and moral rights for the publications made accessible in the public portal are retained by the authors and/or other copyright owners and it is a condition of accessing publications that users recognise and abide by the legal requirements associated with these

- Users may download and print one copy of any publication from the public portal for the purpose of private study or research.

- You may not further distribute the material or use it for any profit-making activity or commercial gain

If the publication is distributed under the terms of Article $25 \mathrm{fa}$ of the Dutch Copyright Act, indicated by the "Taverne" license above, 


\title{
Diminishing covariation bias in women with a negative body evaluation and the potential roles of outcome aversiveness and interpretation of social feedback
}

\author{
Jessica M. Alleva ${ }^{\mathrm{a}, \mathrm{b}, *}$, Bobby G. Stuijfzand ${ }^{\mathrm{c}}$, Carolien Martijn ${ }^{\mathrm{a}}$ \\ a Department of Clinical Psychological Science, Maastricht University, The Netherlands \\ ${ }^{\mathrm{b}}$ Centre for Appearance Research, University of the West of England, Bristol, United Kingdom \\ ' Jean Golding Institute, University of Bristol, Bristol, United Kingdom
}

\section{A R T I C L E I N F O}

\section{Article history:}

Received 26 September 2017

Received in revised form 8 December 2017

Accepted 13 December 2017

Available online 26 December 2017

\section{Keywords:}

Body evaluation

Body image

Covariation bias

Cognitive processing

Social feedback

\begin{abstract}
A B S T R A C T
Women with a more negative body evaluation perceive that their body is associated with more negative social feedback. This covariation bias could reinforce negative body evaluation. We investigated whether covariation bias could be diminished and explored the potential roles of outcome aversiveness and interpretation of negative social feedback associated with one's body. Ninety-seven undergraduate women completed a computer task wherein photos of their body, a control woman's body, and a neutral object were followed by negative social feedback or nothing. When the relation between each category and the negative feedback was random, women with a more negative body evaluation perceived more negative feedback following their body. They also experienced negative feedback following their body and the control woman's body as more aversive. After a manipulation block, women with a more negative body evaluation no longer perceived more negative feedback for their body. These effects coincided with improvements in state body evaluation.
\end{abstract}

(c) 2017 Elsevier Ltd. All rights reserved.

\section{Introduction}

Cognitive-behavioural perspectives of body image propose that body evaluation (i.e., satisfaction or dissatisfaction with one's body) influences cognitive processing, and vice versa (Cash, 2011). For example, research has shown that negative body evaluation is associated with distortions in cognitive processing such as dichotomous thinking and selectively focusing on self-perceived physical flaws (Cash, 2011; Jakatdar, Cash, \& Engle, 2006). In turn, distortions in cognitive processing can reinforce and maintain negative body evaluation (Williamson, White, York-Crowe, \& Stewart, 2004). Similarly, interpersonal experiences and body evaluation mutually affect one another. For example, interpersonal experiences ranging from childhood teasing and bullying to body language and eye gaze can encourage negative body evaluation (Cash \& Fleming, 2002; Fredrickson \& Roberts, 1997; Jones, 2011). Conversely, negative body evaluation can cause individuals to behave in ways that confirm their body concerns (Cash \& Fleming, 2002). For example, if

* Corresponding author at: Department of Clinical Psychological Science, Maastricht University, P.O. Box 616, 6200 MD, Maastricht, The Netherlands.

E-mail address: Jessica.Alleva@maastrichtuniversity.nl (J.M. Alleva). a woman is convinced that she is unattractive, she might inadvertently keep others away by avoiding eye contact or conversation.

Recent research by Alleva and colleagues has integrated cognitive processing and interpersonal experiences in the context of body evaluation, namely by investigating covariation bias (Alleva, Lange, Jansen, \& Martijn, 2014; Alleva, Martijn, \& Jansen, 2016). Covariation bias is a distortion in cognitive processing whereby an individual overestimates the contingency (relationship) between a stimulus and an aversive outcome, even when the contingency is absent or is correlated in the opposite direction (Chapman \& Chapman, 1967). Applied to body image specifically, women with a more negative body evaluation have been found to overestimate the relationship between their own body (the stimulus) and negative social feedback (the aversive outcome; Alleva et al., 2014, 2016). In a first study (Alleva et al., 2014), undergraduate women completed a computer task wherein pictures from three stimulus categories - pictures of one's own body, a control woman's body, or a neutral object - were followed by facial crowds consisting of equal proportions of negative, positive, and neutral social feedback. Images of faces are commonly used to simulate social feedback in research on social anxiety (Hirsch \& Clark, 2004), and produce corresponding physiological responses in participants (e.g., photos of angry faces elicit larger startle responses compared to photos of happy 
faces; Karos, Meulders, \& Vlaeyen, 2014). The results showed that women with a more negative body evaluation perceived that their body was followed by higher levels of negative social feedback, even though there was no contingency between their body and the negative social feedback. This finding was specific for women's own bodies (i.e., not for the other stimulus categories), and was not explained by their interpretation of the social feedback (i.e., how happy vs. angry the portrayed faces were perceived). Research has yet to directly investigate the impact of this covariation bias in daily life, but Alleva et al. (2014) theorised that perceiving that one's own body is followed by higher levels of negative social feedback could confirm negative expectations (e.g., "Everyone really does think that I am unattractive!" p. 229), reinforce negative body evaluation, and even encourage women to behave in ways that elicit negative feedback from others.

In a second study, Alleva and colleagues (2016) investigated in what ways the covariation bias is expressed (Pauli, Montoya, \& Martz, 2001) and whether it could be diminished. To do so, they adapted a computer task by Pauli et al. (2001) that was developed to investigate and diminish covariation bias in panic-prone individuals. This task comprised three blocks, wherein pictures of participants' own body, a control woman's body, and a neutral object were followed by negative social feedback (frowning photos) or nothing (a white screen). In Blocks 1 and 3, each stimulus category was followed by negative social feedback on $50 \%$ of trials (i.e., contingencies were random). In Block 2, designed to diminish the covariation bias, participants' own body and the control woman's body were followed by negative social feedback on $17 \%$ of trials, and the neutral object was followed by negative social feedback on $83 \%$ of trials.

The results showed that, even before the start of the computer task, women with a more negative body evaluation expected their body to be followed by higher levels of negative social feedback. Further, throughout Block 1, women with a more negative body evaluation continued to perceive that their body was followed by more negative social feedback, even though this was not the case. These findings provided evidence for a priori (i.e., before the stimulus-outcome pairings have occurred) and online (i.e., during the presentation of stimuli and outcomes) covariation bias. They suggest that covariation bias exists pre-experimentally, is not merely caused by differential 'online' processing of information, and is resistant to disconfirming situational information (e.g., Amin \& Lovibond, 1997; Pauli et al., 1996). Indeed, at the end of Block 1, women with a more negative body evaluation perceived that their body had been followed by higher levels of negative social feedback during the now-completed block, reflecting a posteriori covariation bias (i.e., after stimulus-outcome pairings have occurred).

Nevertheless, after the manipulation at Block 2, women with a more negative body evaluation no longer perceived that their body was followed by more negative social feedback. That is, despite the persistence of covariation bias in Block 1, reducing the contingency between one's own body and negative social feedback to just $17 \%$ successfully diminished the covariation bias (Pauli et al., 2001). This finding is in line with research suggesting that distortions in cognitive processing are more likely to occur when situational information is ambiguous (Pauli et al., 2001; Wiemer et al., 2014). This might explain why the impact of the computer task on the covariation bias was temporary: When contingencies returned to random at Block 3, women with a more negative body evaluation again reported that their body was followed by more negative social feedback. All findings were specific for women's own bodies (interpretation of the social feedback was not assessed). Interestingly, Alleva et al. (2016) also found that participants' state body evaluation improved from before to after the manipulation at Block 2, and persisted to the end of the computer task. This finding suggests that covariation bias and body evaluation may indeed influence one another.

The current study expanded this research in three important ways. First, although the computer task of Alleva et al. (2016) diminished the covariation bias, these changes did not persist when contingencies returned to random. Therefore, an important step is to determine whether the covariation bias can be more persistently affected. It could be that greater exposure to the reduced contingencies is needed, before covariation bias is more effectively diminished. To this end, the present study employed a computer task with a longer-lasting manipulation block.

Second, although the covariation bias exists pre-experimentally, that does not necessarily mean that it is entirely unaffected by differential online processing. One factor that could play a role is outcome aversiveness: the experienced unpleasantness of the aversive outcome (Wiemer et al., 2014). Studies conducted in spider-fearful individuals have shown that they experience aversive outcomes as more unpleasant following spiders than non-spider-fearful individuals do (e.g., Muhlberger, Wiedemann, Herrmann, \& Pauli, 2006). Enhanced outcome aversiveness could exaggerate stimulus-outcome estimates by consuming greater attentional resources and by preferential encoding of that stimulusoutcome pairing (Wiemer et al., 2014). Similarly, women with a more negative body evaluation might experience negative social feedback associated with their own body as more aversive than women with a less negative body evaluation do. As such, the present study assessed outcome aversiveness associated with each stimulus category.

Third, Alleva et al. (2014) showed that women with a more negative body evaluation did not interpret social feedback differently from women with a less negative body evaluation. Yet, women with a more negative body evaluation might interpret the feedback specifically associated with their own body more negatively. This would reflect a tendency to be harsher towards oneself than others (Neff, 2003), which may be exaggerated in women with a negative body evaluation (Albertson, Neff, \& Dill-Shackleford, 2015). Thus, the current study assessed interpretation of the specific social feedback associated with each stimulus category.

In summary, this study investigated whether a longer-lasting manipulation could diminish the covariation bias more effectively, and explored the potential roles of outcome aversiveness and interpretation of the social feedback associated with one's own body. To do so, undergraduate women completed an adapted version of the computer task of Alleva et al. (2016). First, replicating previous findings (Alleva et al., 2014, 2016), we hypothesised that women with a more negative body evaluation would demonstrate a priori, online, and a posteriori covariation bias. Further, we hypothesised that the longer-lasting manipulation block would diminish the covariation bias, and that these effects would persist at the end of the computer task. We also predicted these effects to coincide with improvements in state body evaluation. Last, we predicted that women with a more negative body evaluation would experience negative social feedback associated with their own body as more aversive and would interpret this feedback more negatively - compared to women with a less negative body evaluation.

\section{Method}

\subsection{Participants}

Participants were 97 women between 18 and 30 years old $\left(M_{\mathrm{age}}=21.07, S D=2.51\right)$ with body mass indices (BMI) between 17.01 and $29.27\left(M_{\mathrm{BMI}}=21.40, S D=2.23\right)$. Most participants were university students (94.8\%) of German (40\%) or Dutch $(22 \%)$ descent. The remainder reported being of another European (28\%), 
Asian (5\%), North American (3\%), or Mixed (2\%) descent. They identified as heterosexual (91\%), bisexual (8\%), or did not provide an answer (1\%). An additional five participants completed the study but were not included in the dataset as they were aware of the study's aims $(n=3)$ or their data had not been correctly saved $(n=2)$.

\subsection{Materials}

\subsubsection{Computer task}

The computer task was delivered via Presentation (Neurobiological Systems Inc., 2017). Participants were instructed to discover whether there was a relationship between three categories of pictures (their body, another woman's body, and a lamp) and two outcomes (a negative portrait photo or nothing). Blocks 1 and 3 comprised 12 trials per stimulus category, and each stimulus category was followed by negative social feedback on $50 \%$ of trials (Alleva et al., 2016; Pauli et al., 2001). Block 2 comprised 24 trials per stimulus category and, in this block, pictures of women's own body and the control woman's body were followed by negative social feedback on $17 \%$ of trials, and pictures of the neutral object were followed by negative social feedback on $83 \%$ of trials (Alleva et al., 2016; Pauli et al., 2001). Pictures of each category were shown for six seconds each, and the negative social feedback (or white screen) was shown for two seconds. Pictures of the three categories were presented in random order, with the constraint that pictures of a given category could not be presented on more than two consecutive trials in Blocks 1 and 3. This computer task is based on Pauli et al. (2001) and Alleva et al. (2016). However, in this study, Block 2 comprised 24 trials instead of 12 trials. See Alleva et al. (2016) for further details.

\subsubsection{Pictorial stimuli}

Three categories of pictures, consisting of three pictures each, were used in the computer task (Alleva et al., 2016). Pictures of the control woman and the participants were full-body photographs taken from the front and both sides. The control woman was a graduate student of average BMI, wearing a form-fitting black tshirt and pants. She looked straight into the camera, with a neutral expression and her arms at her sides. Participants were similarly photographed. Pictures of a standing lamp, photographed from the front and both sides, were chosen for the neutral object. Portrait photos from the validated NimStim Facial Stimuli Set (Tottenham et al., 2009) comprised the negative social feedback. These portrait photos were of nine women and nine men, all frowning (mouth closed). Each portrait photo appeared twice in Blocks 1 and 3, and four times in Block 2.

\subsubsection{Covariation estimates}

Three types of covariation estimates were assessed during the computer task (Alleva et al., 2016; Pauli et al., 2001). A priori covariation estimates concerned the expected relationship between each stimulus category and the negative social feedback, e.g., "How strongly do you expect that pictures of your own body will be followed by a negative (frowning) portrait photo?" Online covariation estimates assessed the perceived present-moment relationship between each stimulus category and the negative social feedback, e.g., "You just saw a picture of your own body. How strongly do you expect that the next time you see a picture of your own body, it will be followed by a negative (frowning) portrait photo?" A posteriori covariation estimates assessed the perceived relationship that had occurred between each stimulus category and the negative social feedback, e.g., "Given that you saw pictures of your own body, on what percentage of those trials was your own body followed by a negative (frowning) portrait photo?" Estimates were rated on visual analogue scales (VAS) from 0 to 100 (e.g., $0=$ Definitely DO NOT expect that a negative portrait photo will follow pictures of my own body, 100 = Definitely DO expect that a negative portrait photo will follow pictures of my own body).

\subsubsection{Outcome aversiveness}

Participants rated how unpleasant they experienced the negative social feedback that followed each stimulus category, e.g., "How unpleasant did you experience the negative (frowning) portrait photos that followed pictures of your own body?", on VAS from $0=$ not unpleasant at all to $100=$ very unpleasant (Wiemer et al., 2014). Higher scores reflect greater outcome aversiveness for the social feedback following the respective stimulus category.

\subsubsection{Interpretation ratings}

Participants rated all portrait photos on VAS from $0=$ very happy to $100=$ very angry (Alleva et al., 2014). The computer task tracked which photos were associated with which stimulus category, allowing us to calculate separate means for the social feedback associated with each stimulus category. Higher scores reflect a more negative evaluation of the social feedback for the respective stimulus category.

\subsubsection{Base-rate estimates}

Participants indicated the percentage of trials, taking all stimulus categories together, which were followed by negative social feedback: "Taking all three categories of pictures together, on which percentage of trials were pictures followed by a negative (frowning) portrait photo?"(Alleva et al., 2016; Pauli et al., 2001). They also indicated the percentage of trials, taking all blocks together, which concerned each stimulus category, e.g., "Taking all three blocks together, what percentage of the pictures presented were pictures of your own body?" (Alleva et al., 2016; Pauli et al., 2001). Estimates were rated on VAS from $0 \%$ to $100 \%$. Base-rate estimates are helpful to check that the covariation bias is not merely explained by differences in perception of the amount of negative social feedback or the number of trials of each stimulus category.

\subsubsection{Trait body evaluation}

Trait body evaluation was measured using the Appearance Evaluation (seven items; e.g., "Most people would consider me good-looking") and Body Areas Satisfaction (nine items; e.g., satisfaction with weight) Subscales (Multidimensional Body-Self Relations Questionnaire; Brown, Cash, \& Mikulka, 1990; Cash, 2000). Subscale items are rated from $1=$ definitely disagree to $5=$ definitely agree and $1=$ very dissatisfied to 5=very satisfied, respectively. Scores on these 16 items were averaged, and lower scores reflect a more negative trait body evaluation (Cash, 2000). Scores on this measure demonstrated good one-month test-retest reliability and construct validity in adult women (Cash, 2000). In this study, Cronbach's alpha for the items of these subscales together was .89 , comparable to prior research in similar samples (e.g., Alleva et al., 2014, $\alpha=.88$; Alleva et al., 2016, $\alpha=.90$ ).

\subsubsection{State body evaluation}

State body evaluation was measured using two VAS items assessing participants' current level of physical appearance satisfaction and dissatisfaction (reverse-coded) from $0=$ none to $100=$ extreme (Birkeland et al., 2005), interspersed with filler items. Scores were averaged, and lower scores reflect a more negative state body evaluation (Birkeland et al., 2005). Scores on this measure demonstrated 5-min test-retest reliability and are sensitive to experimental manipulations (Birkeland et al., 2005). In this study, Cronbach's alpha ranged from .82 to .90 across measurements, comparable to prior research in similar samples (e.g., Alleva et al., 2016, $\alpha=.86$ to .91 ). 


\subsection{Procedure}

Maastricht University's ethics committee approved this study. Participants were recruited via campus advertisements for a study about "discovering patterns between pictures." Participants signed an informed consent sheet and completed the trait body evaluation measure. Next, they changed into a form-fitting black t-shirt and pants in their desired size (XXS-XXL); they were photographed in front of a white screen from the front and both sides, looking straight into the camera with a neutral expression and arms at their sides (Alleva et al., 2016).

One week later, participants completed the computer task, which was interspersed with the remaining measures: A priori covariation estimates were collected before the start of Block 1, online covariation estimates were collected during each block (immediately following each trial), and a posteriori covariation estimates were collected after each block (Alleva et al., 2016; Pauli et al., 2001). Outcome aversiveness and interpretation ratings were collected after Block 1. Base rate estimates were collected after each block, and state body evaluation was assessed before the start of Block 1 and after each block (Alleva et al., 2016; Pauli et al., 2001). Given the length of the computer task, participants received 5-min breaks before Blocks 2 and 3 to prevent fatigue. They were given neutral word search puzzles and were told that the purpose of the breaks was to rest and it did not matter how many words they found. At the end of the session, participants described the study's aims (as an awareness check) and chose research credit or a gift voucher. Debriefing occurred at study completion.

\subsection{Statistical analyses}

First, to investigate whether women with a more negative body evaluation would demonstrate a priori, online, and a posteriori covariation bias, we tested the relationships between trait and state body evaluation and the covariation estimates using Pearson product-moment correlation coefficients. The covariation estimates concerned the a priori covariation estimates collected before Block 1, the online covariation estimates collected during Block 1 (averaged per stimulus category), and the a posteriori covariation estimates collected after Block 1. We also tested the relationships between trait and state body evaluation and the baserate estimates to check that results were not likely to be explained by differences in perception of the amount of negative social feedback or the number of trials of each stimulus category.

Second, to investigate whether women with a more negative body evaluation would no longer estimate higher levels of negative social feedback at the end of Block 2, and that these effects would persist at the end of the computer task, we tested the relationships between trait and state body evaluation and the a posteriori covariation estimates collected after Blocks 2 and 3 using Pearson product-moment correlation coefficients.

Third, we investigated whether state body evaluation would improve from before to after the manipulation at Block 2, and whether any effects would persist to the end of Block 3. To do so, we conducted planned comparisons of the marginal means of state body evaluation as measured prior to Block 2, directly after Block 2 , and directly after Block 3 . The marginal means were based on a multilevel model where measurements of state body evaluation were nested within participants, whilst controlling for Baseline levels of state body evaluation, as measured at the start of the computer task. These analyses were conducted in $\mathrm{R}$ ( $\mathrm{R}$ Core Team, 2017) using the lme4 (Bates, Maechler, Bolker, \& Walker, 2015) and lsmeans (Lenth, 2016) packages.

Fourth, to investigate whether women with a more negative body evaluation would experience negative social feedback associated with their body as more aversive than women with a less negative body evaluation do, we tested the relationships between trait and state body evaluation and outcome aversiveness for negative social feedback following the own body using Pearson product-moment correlation coefficients.

Last, to test whether women with a more negative body evaluation would interpret the negative social feedback associated with their body as more negative than women with a less negative body evaluation do, we tested the relationships between trait and state body evaluation and the interpretation ratings for negative social feedback associated with the own body using Pearson productmoment correlation coefficients.

When calculating the Pearson product-moment correlation coefficients as described above, state body evaluation refers to state body evaluation as measured before the start of the computer task. To interpret the Pearson product-moment correlation coefficients, we used Cohen's (1992) guidelines whereby $r=.10, .30$, and .50 indicate weak, moderate, and strong correlations, respectively. To test the specificity of the results, the analyses were repeated with the data concerning the other stimulus categories. Finally, where multiple testing was conducted, we applied Bonferroni adjustments to the $p$-values within each family of tests (i.e., whereby the alpha value of .05 was divided by the number of tests).

\section{Results}

\subsection{Presence of covariation bias}

For the following sets of analyses, an alpha value of .005 was adopted (i.e., .05/10 tests per trait and state body evaluation). Trait body evaluation was significantly and moderately to strongly associated with women's a priori, $r=-.47, p<.001$, online, $r=-.37$, $p<.001$, and a posteriori, $r=-.39, p<.001$, covariation estimates concerning their own body. Similarly, state body evaluation was significantly and moderately to strongly associated with women's a priori, $r=-.54, p<.001$, online, $r=-.35, p<.001$, and $a$ posteriori, $r=-.36, p<.001$, covariation estimates for their own body. The negative Pearson product-moment correlation coefficients show that women with lower scores on the measures of trait and state body evaluation (i.e., with a more negative body evaluation) estimated higher levels of negative social feedback for their own body $-a$ priori, online, and a posteriori.

Neither trait nor state body evaluation was significantly associated with women's a priori, online, and a posteriori covariation estimates for the other stimulus categories ( $p s>.005$ ), indicating that the covariation bias is specific for women's own body. In addition, trait body evaluation, $r=-.28, p=.006$, and state body evaluation, $r=-.22, p=.031$, were not significantly associated with women's base rate estimates collected after Block 1. Therefore, women's perception of the percentage of trials overall (across Block 1) that were followed by negative social feedback did not significantly depend on their trait or state body evaluation.

\subsection{Diminishing covariation bias}

For the following sets of analyses, an alpha value of .005 was adopted (i.e., .05/11 tests per trait and state body evaluation). After Block 2, trait body evaluation, $r=-.16, p=.110$, and state body evaluation, $r=-.12, p=.237$, were no longer significantly associated with women's covariation estimates for their own body. Further, at the end of Block 3, after contingencies had returned to random, both trait body evaluation, $r=-.22, p=.030$, and state body evaluation, $r=-.24, p=.016$, were no longer significantly associated with women's covariation estimates for their own body. Collectively, these findings suggest that after the manipulation at Block 2, women with lower scores on the measures of trait and state body 


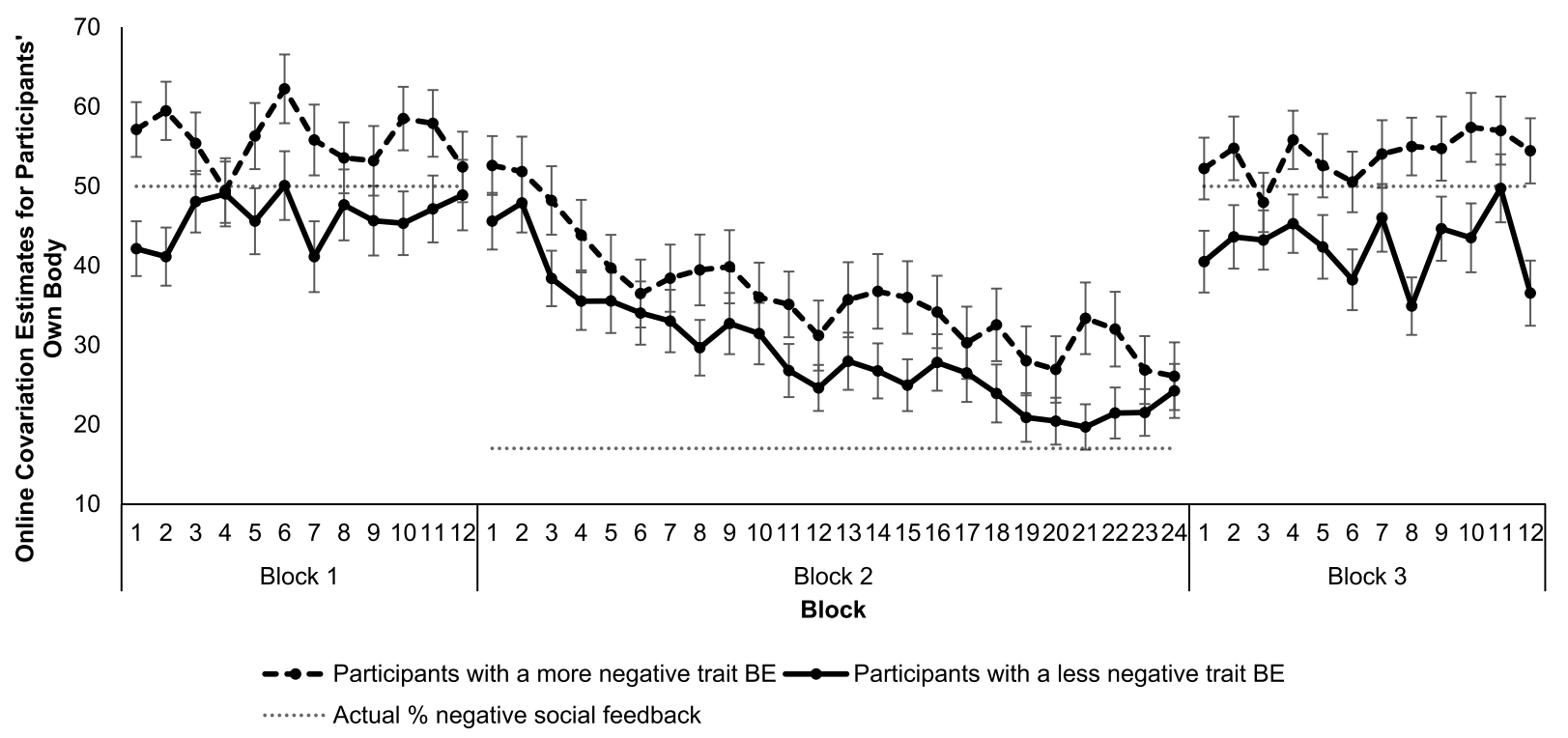

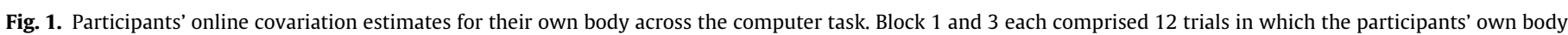

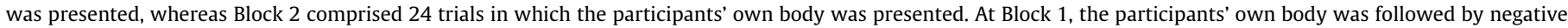

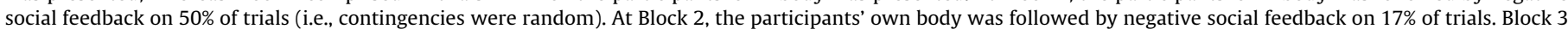
was identical to Block 1 . BE = body evaluation. Error bars represent standard errors.

evaluation (i.e., with a more negative body evaluation) no longer estimated higher levels of negative social feedback for their own body, and these effects persisted to the end of the computer task.

No significant results were found when these analyses were repeated concerning the other stimulus categories (all ps >.005). Further, neither trait nor state body evaluation were significantly associated with women's base rate estimates collected after Blocks 2 and 3 (all ps > .005): Women with varying levels of negative body evaluation did not differ concerning the overall perceived percentage of trials followed by negative social feedback (Blocks 2 and 3) or the overall perceived percentage of trials of each stimulus category (across the computer task).

To provide additional insight into women's covariation estimates across the computer task, we plotted their online covariation estimates for each trial (per block) in which their own body was presented (Fig. 1). Data were plotted for women with a more vs. less negative trait body evaluation (i.e., those with lower vs. higher scores on the measure of trait body evaluation), as determined by a median split. The figure appears to confirm the analyses described above. That is, during Block 1, women with a more negative body evaluation estimated higher levels of negative social feedback for their own body. During the manipulation at Block 2, women's covariation estimates decreased across the trials. At Block 3, covariation estimates seem to have risen, but the analyses suggest that women with a more negative body evaluation no longer estimated significantly higher levels of negative social feedback for their own body compared to women with a less negative body evaluation. Note that Fig. 1 must be interpreted with caution, given the dichotomous categorisation of body evaluation.

\subsection{Changes in state body evaluation}

For the following analyses, an alpha value of .025 was used (i.e., .05/2 tests). Planned comparisons indicated that there was a significant difference between state body evaluation before and after Block 2, while controlling for Baseline state body evaluation. Examining the marginal means showed that state body evaluation improved after completing the manipulation at Block 2, $M_{\text {difference }}=3.63, t(192)=3.54, p<.001$. A lack of significant change from after Block 2 and after Block 3 indicates that this improvement in state body evaluation persisted to the end of the computer task, $M_{\text {difference }}=0.49, t(192)=0.48, p=.633$.

\subsection{Outcome aversiveness}

An alpha value of .017 was adopted for these analyses (i.e., .05/3 tests per trait and state body evaluation). Both trait body evaluation, $r=-.41, p<.001$, and state body evaluation, $r=-.40, p<.001$, were significantly and moderately related to women's outcome aversiveness for negative social feedback associated with their body. However, trait body evaluation, $r=-.27, p=.007$, and state body evaluation, $r=-.31, p=.002$, were also significantly related to women's outcome aversiveness for negative social feedback associated with the control woman's body. Results were nonsignificant concerning the neutral object (all ps $>.017$ ). These findings show that women with lower scores on the measures of trait and state body evaluation (i.e., with a more negative body evaluation) perceived negative social feedback associated with both their own body and the control woman's body as more aversive compared to women with higher scores on these measures (i.e., with a less negative body evaluation).

\subsection{Interpretation ratings}

An alpha value of .017 was adopted for these analyses (i.e., .05/3 tests per trait and state body evaluation). Neither trait body evaluation, $r=-.05, p=.658$, nor state body evaluation, $r=-.02, p=.819$, were significantly related to women's interpretation ratings for the negative social feedback associated with their own body. Likewise, the results were nonsignificant for women's ratings for the negative social feedback associated with the other stimulus categories (all $p s>.017$ ). Thus, women with varying levels of negative body evaluation did not differ concerning how they interpreted the negative social feedback associated with their own body, the control woman's body, and the neutral object. 


\section{Discussion}

This study investigated whether a longer-lasting manipulation could diminish the covariation bias more effectively, and explored the potential roles of outcome aversiveness and interpretation of the negative social feedback associated with the own body. First, in line with prior research (Alleva et al., 2014, 2016), women with a more negative body evaluation perceived higher levels of negative social feedback for their body - expressed a priori, online, and $a$ posteriori. These findings underscore that the covariation bias exists pre-experimentally, is not merely caused by differential 'online' processing of information, and is resistant to disconfirming situational information (e.g., Amin \& Lovibond, 1997; Pauli et al., 1996). As hypothesised, the longer-lasting manipulation seemed to be effective at diminishing the covariation bias, both immediately after the manipulation and - in contrast to Alleva et al. (2016) - at the end of the computer task, where contingencies had returned to random. That is, compared to women with a less negative body evaluation, women with a more negative body evaluation no longer estimated higher levels of negative social feedback for their own body.

These results are promising, especially considering that covariation bias is more likely to occur when situational information is ambiguous, as when one's body is followed by negative social feedback on 50\% of trials (Pauli et al., 2001; Wiemer et al., 2014). The current manipulation may have given women greater opportunity to challenge their cognitive distortions, and they might have transferred what they had learned to a novel and ambiguous situation at Block 3. Although we are optimistic that this manipulation could eventually be used to diminish covariation bias outside the laboratory, repeated practice will likely be needed to obtain lasting improvements. Future research should investigate the longer-term effects of the manipulation and explore the impact of multiple-session variants, as have been developed for other forms of cognitive bias modification (see Hallion \& Ruscio, 2011 , for a review). It will also be insightful to investigate whether diminishing the covariation bias would be beneficial in specific target groups where negative body evaluation is especially high and plays an aetiological and perpetuating role, such as in individuals with an eating disorder (Crowther \& Williams, 2011; Delinsky, 2011) or body dysmorphic disorder (Phillips, 2011).

Interestingly, in line with Alleva et al. (2016), the manipulation of the covariation bias coincided with improvements in state body evaluation. This finding suggests that covariation bias could indeed play a role in reinforcing or maintaining negative body evaluation, and supports the value of the manipulation for intervention. More broadly, this finding also supports the proposed interplay between cognitive processing, interpersonal experiences, and body evaluation (e.g., Cash, 2011; Cash \& Fleming, 2002; Williamson et al., 2004). However, it is also possible that state body evaluation improved because women were repeatedly exposed to images of their own body. Indeed, studies have shown that exposure to one's own body can lead to improvements in body image (Alleva, Sheeran, Webb, Martijn, \& Miles, 2015), although such exposure is usually guided, for example to train participants to focus on their self-perceived attractive body parts (Jansen et al., 2016). Nevertheless, to discern whether the effects are specifically caused by the covariation bias manipulation, future research could incorporate a condition wherein contingencies are not manipulated at Block 2 .

Unexpectedly, women with a more negative body evaluation experienced negative social feedback following body-related stimuli - both their own and a control woman's body - as more aversive than women with a less negative body evaluation. It could be that negative social feedback following other women's bodies is also perceived as self-relevant to women with a more negative body evaluation. For example, how other women's bodies are evaluated could provide useful information about how one's own body will be evaluated. Interestingly, these findings are not in line with research showing that experimentally heightening outcome aversiveness (e.g., using startle sounds of different intensities) is sufficient to drive the formation of covariation bias for neutral stimuli (Wiemer et al., 2014). Applied to this study, women with a more negative body evaluation should have thus also shown a covariation bias for the relation between the control woman's body and negative social feedback, which was not the case. Together, the current findings suggest that outcome aversiveness may play a role in maintaining covariation bias, but it may not be sufficient for the existence or formation of covariation bias. Last, women with a more vs. less negative body evaluation did not differ in their interpretation of the negative social feedback - neither with respect to the feedback overall (Alleva et al., 2014) nor for their body specifically. Taking the foregoing discussion into account, women with a more negative body evaluation do not seem to interpret negative social feedback differently than women with a less negative body evaluation, but they do experience it differently: as more aversive (concerning body-related stimuli).

As described earlier, it is important to target women's covariation bias for the relation between their own body and negative social feedback, as it could serve to confirm negative expectations, reinforce negative body evaluation, and even encourage behaviours that elicit negative feedback from others (Alleva et al., 2014). An important direction for future research is to investigate the impact of this covariation bias on women's daily lives, as this has not been directly tested before. For example, similar to research testing the impact of media on women's daily lives (e.g., Fardouly, Pinkus, \& Vartanian, 2017), ecological momentary assessment could be used to track daily patterns of covariation estimates and body evaluation, and cognitions (e.g., expectations of social rejection) and behaviours (e.g., avoidance of social activities) of interest. Relatedly, future research could investigate how the covariation bias relates to other aspects of negative (e.g., upward social comparison tendencies) and positive (e.g., perceived unconditional body acceptance from others; Avalos \& Tylka, 2006) body image, as well as physical (e.g., intuitive eating; Tylka \& Kroon Van Diest, 2013) and psychological (e.g., self-esteem) health.

One limitation of this study is that, as the computer task was modelled after Pauli et al. (2001), just two outcome categories were used: negative social feedback or nothing. Future variants could incorporate positive and neutral social feedback for a more ecologically-valid simulation of interpersonal experiences. Second, participants' interpretation of the negative social feedback was assessed based on how happy vs. angry they perceived the faces to be. This decision was made in line with prior research (Alleva et al., 2014), but future investigations could assess perceived happiness and anger on separate dimensions, and include additional indices of interpretation (e.g., disgust). Third, as our sample was comprised of mainly undergraduate women of German and Dutch descent, replicating this research in individuals of other ages, genders, ethnic backgrounds, and additional social identities is needed. Fourth, we recruited women with varying scores on the measures of body evaluation. However, in line with research in the field of anxiety (e.g., Muhlberger et al., 2006), it would also be insightful to investigate covariation bias among two dichotomous groups of women with extremely low vs. extremely high scores on these measures. Last, it remains to be determined whether women's covariation estimates as assessed within the laboratory translate to their perceptions of social feedback in their social environment. Ecological momentary assessment could be used to explore this possibility, although it would be challenging to determine how women's perceptions differ from reality in uncontrolled settings.

Despite these limitations, this study is valuable because it represents an important step in integrating research on distortions in cognitive processing and interpersonal experiences in the con- 
text of body evaluation. It extended the literature by (a) providing additional support for the covariation bias in women with a more negative body evaluation, (b) testing a longer-lasting manipulation to diminish the covariation bias, and (c) exploring the potential roles played by outcome aversiveness and interpretation of social feedback associated with one's body. This study also investigated an additional psychological factor that can explain the maintenance or aetiology of negative body evaluation, and thus identified an additional factor that could be targeted in interventions designed to improve body evaluation.

\section{Acknowledgements}

The contribution of Jessica M. Alleva was supported by NWO grant 404-10-118: Novel strategies to enhance body satisfaction, awarded to Carolien Martijn. We would like to thank Jacco Ronner for programming the computer task for this study, and Julian Wiemer for his advice on how to best assess outcome aversiveness in the present sample. We would also like to thank Kai Karos for his help with collating the data files from the computer task. Last, we would like to thank Franziska Kienzler, Camilla Parigger, and Lin Qiu for their help with recruiting and testing participants.

\section{References}

Albertson, E. R., Neff, K. D., \& Dill-Shackleford, K. E. (2015). Self-compassion and body dissatisfaction in women: A randomized controlled trial of a brief meditation intervention. Mindfulness, 6, 444-454. http://dx.doi.org/10.1007/ s12671-014-0277-3

Alleva, J. M., Lange, W. G., Jansen, A., \& Martijn, C. (2014). Seeing ghosts: Negative body evaluation predicts overestimation of negative social feedback. Body Image, 11, 228-232. http://dx.doi.org/10.1016/j.bodyim.2014.03.001

Alleva, J. M., Sheeran, P., Webb, T. L., Martijn, C., \& Miles, E. (2015). A meta-analytic review of interventions designed to improve body image. PLoS One, 10, e0139177. http://dx.doi.org/10.1371/journal.pone.0139177

Alleva, J. M., Martijn, C., \& Jansen, A. (2016). Covariation bias in women with a negative body evaluation: How is it expressed and can it be diminished? Journal of Behavior Therapy and Experimental Psychiatry, 50, 33-39. http://dx. doi.org/10.1016/j.jbtep.2015.04.012

Amin, J. M., \& Lovibond, P. F. (1997). Dissociations between covariation bias and expectancy bias for fear-relevant stimuli. Cognition \& Emotion, 11, 273-289. http://dx.doi.org/10.1080/026999397379926

Avalos, L. C., \& Tylka, T. L. (2006). Exploring a model of intuitive eating with college women. Journal of Counseling Psychology, 53, 486-497. http://dx.doi.org/10. 1037/0022-0167.53.4.486

Bates, D., Maechler, M., Bolker, B., \& Walker, S. (2015). Fitting linear mixed-effects models using lme4. Journal of Statistical Software, 67, 1-48. http://dx.doi.org/ 10.18637/jss.v067.i01

Birkeland, R., Thompson, J. K., Herbozo, S., Roehrig, M., Cafri, G., \& van den Berg, P. (2005). Media exposure, mood, and body image dissatisfaction: An experimental test of person versus product priming. Body Image, 2, 53-61. http://dx.doi.org/10.1016/j.bodyim.2004.11.002

Brown, T. A., Cash, T. F., \& Mikulka, P. J. (1990). Attitudinal body-image assessment: Factor analysis of the Body-Self Relations Questionnaire. Journal of Personality Assessment, 55, 135-144. http://dx.doi.org/10.1207/s15327752jpa5501\&2_13

Cash, T. F., \& Fleming, E. C. (2002). Body image and social relations. In T. F. Cash \& T. Pruzinsky (Eds.), Body image: A handbook of theory, research, and clinical practice (pp. pp. 277-286). New York, NY: Guilford Press

Cash, T. F. (2000). Multidimensional Body-Self Relations Questionnaire users' manual (3rd revision). [Available from the author at]. www.body-images.com

Cash, T. F. (2011). Cognitive-behavioral perspectives on body Image. In T. F. Cash \& L. Smolak (Eds.), Body image: A handbook of science, practice, and prevention (pp. pp. 39-47). New York, NY: Guilford Press.

Chapman, L. J., \& Chapman, J. P. (1967). Genesis of popular but erroneous psycho-diagnostic observations. Journal of Abnormal Psychology, 72, 193-204.

Cohen, J. (1992). A power primer. Psychological Bulletin, 112, 155-159. http://dx. doi.org/10.1037/0033-2909.112.1.155
Crowther, J. H., \& Williams, N. M. (2011). Body image and bulimia nervosa. In T. F. Cash \& L. Smolak (Eds.), Body image: A handbook of science, practice, and prevention (pp. 288-295). New York, NY: Guilford Press.

Delinsky, S. S. (2011). Body image and anorexia nervosa. In T. F. Cash \& L. Smolak (Eds.), Body image: A handbook of science, practice, and prevention ( $\mathrm{pp}$ 279-287). New York, NY: Guilford Press.

Fardouly, J., Pinkus, R. T., \& Vartanian, L. R. (2017). The impact of appearance comparisons made through social media, traditional media, and in person in women's everyday lives. Body Image, 20, 31-39. http://dx.doi.org/10.1016/j. bodyim.2016.11.002

Fredrickson, B. L., \& Roberts, T.-A. (1997). Objectification theory: Toward understanding women's lived experiences and mental health risks. Psychology of Women Quarterly, 21, 173-206. http://dx.doi.org/10.1111/j.1471-6402.1997. tb00108.x

Hallion, L. S., \& Ruscio, A. M. (2011). A meta-analysis of the effect of cognitive bias modification on anxiety and depression. Psychological Bulletin, 137, 940-958. http://dx.doi.org/10.1037/a0024355

Hirsch, C. R., \& Clark, D. M. (2004). Information-processing bias in social phobia. Clinical Psychology Review, 24, 799-825. http://dx.doi.org/10.1016/j.cpr.2004 07.005

Jakatdar, T. A., Cash, T. F., \& Engle, E. K. (2006). Body-image thought processes: The development and initial validation of the Assessment of Body-Image Cognitive Distortions. Body Image, 3, 325-333. http://dx.doi.org/10.1016/j.bodyim.2006. 09.001

Jansen, A., Voorwinde, V., Hoebink, Y., Rekkers, M., Martijn, C., \& Mulkens, S. (2016). Mirror exposure to increase body satisfaction: Should we guide the focus of attention towards positively or negatively evaluated body parts? Journal of Behavior Therapy and Experimental Psychiatry, 50, 90-96. http://dx. doi.org/10.1016/j.jbtep.2015.06.002

Jones, D. C. (2011). Interpersonal and familial influences on the development of body image. In T. F. Cash \& L. Smolak (Eds.), Body image: A handbook of science, practice, and prevention (pp. pp. 110-118). New York, NY: Guilford Press.

Karos, K., Meulders, A., \& Vlaeyen, J. W. S. (2014). Threatening social context facilitates pain-related fear learning. Journal of Pain, 16, 214-225. http://dx.doi. org/10.1016/j.jpain.2014.11.014

Lenth, R. V. (2016). Least-squares means: The R package lsmeans. Journal of Statistical Software, 69, 1-33. http://dx.doi.org/10.18637/jss.v069.i01

Muhlberger, A., Wiedemann, G., Herrmann, M. J., \& Pauli, P. (2006). Phylo- and ontogenetic fears and the expectation of danger: Differences between spiderand flight-phobic subjects in cognitive and physiological responses to disorder-specific stimuli. Journal of Abnormal Psychology, 115, 580-589. http:// dx.doi.org/10.1037/0021-843X.115.3.580

Neff, K. (2003). Self and identity self-compassion: An alternative conceptualization of a healthy attitude toward oneself. Self and Identity, 2, 85-101. http://dx.doi. org/10.1080/15298860309032

Neurobiological Systems Inc. (2017). Presentation [computer software]. [Retrieved from]. https://www.neurobs.com/

Pauli, P., Montoya, P., \& Martz, G. E. (1996). Covariation bias in panic-prone individuals. Journal of Abnormal Psychology, 105, 658-662. http://dx.doi.org/10. 1037/0021-843X.105.4.658

Pauli, P., Montoya, P., \& Martz, G. E. (2001). On-line and a posteriori covariation estimates in panic-prone individuals: Effects of a high contingency of shocks following fear-irrelevant stimuli. Cognitive Therapy and Research, 25, 23-36. http://dx.doi.org/10.1023/A:1026470514475

Phillips, K. A. (2011). Body image and body dysmorphic disorder. In T. F. Cash \& L. Smolak (Eds.), Body image: A handbook of science, practice, and prevention (pp. 305-313). New York, NY: Guilford Press.

R Core Team. (2017). R: A language and environment for statistical computing. Vienna, Austria: R Foundation for Statistical Computing. https://www.Rproject.org/

Tottenham, N., Tanaka, J., Leon, A. C., McCarry, T., Nurse, M., Hare, T. A., . . \& \& Nelson, C. A. (2009). The NimStim set of facial expressions: Judgments from untrained research participants. Psychiatry Research, 168, 242-249. http://dx doi.org/10.1016/j.psychres.2008.05.006

Tylka, T. L., \& Kroon Van Diest, A. M. (2013). The Intuitive Eating Scale-2: Item refinement and psychometric evaluation with college women and men. Journal of Counseling Psychology, 60, 137-153. http://dx.doi.org/10.1037/a0030893

Wiemer, J., Mühlberger, A., \& Pauli, P. (2014). Illusory correlations between neutral and aversive stimuli can be induced by outcome aversiveness. Cognition and Emotion, 28, 193-207. http://dx.doi.org/10.1080/02699931.2013.809699

Williamson, D. A., White, M. A., York-Crowe, E., \& Stewart, T. M. (2004). Cognitive-behavioral theories of eating disorders. Behavior Modification, 28, 711-738. http://dx.doi.org/10.1177/01454455032598 